\title{
The epidemiology of infantile hypertrophic pyloric stenosis in Sweden 1987-96
}

\author{
G Hedbäck, K Abrahamsson, B Husberg, T Granholm, A Odén
}

\begin{abstract}
Aims-To find out whether the incidence of infantile hypertrophic pyloric stenosis (IHPS) has changed over the past decade, and if so, to investigate possible contributory factors.

Methods-All infants undergoing pyloromyotomy for IHPS in Sweden between 1987 and 1996 were studied. Using the national patient registers the yearly incidence was determined and evaluated in relation to sex, latitude, urbanisation, and type of surroundings by use of a Poisson model.

Results-There was a substantial decline from $2.7 / 1000$ to $0.85 / 1000$ over the time period. The incidence in the south was almost three times greater than in the north.

Conclusion-The declining incidence and geographical difference suggest that environmental factors are of importance in this disorder.
\end{abstract}

(Arch Dis Child 2001;85:379-381)

Keywords: pyloric stenosis; incidence; geographical variation; pyloromyotomy

For some years, we have had an impression that there has been a decline in the incidence of infantile hypertrophic pyloric stenosis (IHPS). This study was performed to investigate this observation, and if a decline has taken place, to investigate factors that might have contributed to it. Changes in the incidence of IHPS, both upwards ${ }^{1-6}$ and downwards, ${ }^{7-9}$ have previously been reported.

Department of

Mathematics and

Statistics, University of

Gothenburg,

Gothenburg, Sweden

A Odén

Correspondence to: Dr Hedbäck

g.hedback@home.se

Accepted 12 July 2001

\section{Patients and methods}

All patients cared for as in-patients at medical facilities in Sweden are registered with the National Patient Registry which is maintained by the Swedish National Board of Health and Welfare. Using this registry, we identified all patients with a diagnosis of IHPS (No. 750F, ICD-9 $)^{10}$ during the years 1987-96. The

Table 1 Numbers of male and female infants with IHPS, total number of live births, and yearly incidence of IHPS in Sweden during the years 1987-96

\begin{tabular}{lccccc}
\hline Year & $\begin{array}{l}\text { Male infants } \\
\text { with IHPS }\end{array}$ & $\begin{array}{l}\text { Female infants } \\
\text { with IHPS }\end{array}$ & $\begin{array}{l}\text { All infants with } \\
\text { IHPS }\end{array}$ & $\begin{array}{l}\text { Number of live } \\
\text { births }\end{array}$ & $\begin{array}{l}\text { Incidence per } \\
\text { 1000 births }\end{array}$ \\
\hline 1987 & 233 & 40 & 273 & 104699 & 2.607 \\
1988 & 242 & 58 & 300 & 111086 & 2.701 \\
1989 & 234 & 82 & 316 & 114788 & 2.753 \\
1990 & 224 & 61 & 285 & 122172 & 2.333 \\
1991 & 188 & 49 & 237 & 123142 & 1.925 \\
1992 & 195 & 44 & 239 & 122199 & 1.956 \\
1993 & 129 & 31 & 160 & 116606 & 1.372 \\
1994 & 113 & 24 & 137 & 110570 & 1.239 \\
1995 & 110 & 20 & 130 & 101752 & 1.278 \\
1996 & 70 & 10 & 80 & 94384 & 0.848 \\
All & 1738 & 419 & 2157 & 1121398 & 1.923 \\
\hline
\end{tabular}

patient series studied consisted of those individuals who were reported to have undergone pyloromyotomy (No. 4410, Classification of Surgical Interventions). ${ }^{11}$ For reasons of patient confidentiality, the registry did not allow determination of the precise age at surgery; however, all patients were less than 1 year old. The inclusion date of a patient was the date of arrival at the hospital before surgery. No one was included in the patient series more than once.

In each case patients were registered with respect to date of arrival at the hospital, sex, county, and local district of residence. The total number of patients treated each year was determined as was the total number of births each year, together with their sex and geographical location. ${ }^{12}$ Sweden consists of 24 counties subdivided into 288 local districts.

The probability $(\mathrm{F})$ of a child undergoing pyloromyotomy for IHPS during the first year of life was estimated using a Poisson model ${ }^{13}$ incorporating the following factors: sex (X), time as year and date $(\mathrm{Y})$, and latitude $(\mathrm{Z})$, so that:

$$
F=\exp \left(\beta_{0}+\beta_{1} X+\beta_{2} Y+\beta_{3} Z\right)
$$

where $\beta_{0}$ is a constant, $\mathrm{X}=0$ for boys, and $\mathrm{X}=1$ for girls, $\mathrm{Y}$ is the number of days after 31 December 1986, and $\mathrm{Z}$ is the latitude (in degrees) of the main town or city of the county in question. The $\beta$ coefficients, their standard errors (SE), and their two sided $\mathrm{p}$ values were estimated according to the maximum likelihood method.

Equation 1 was modified by adding $\beta_{4} \mathrm{Y} \cdot \mathrm{Z}$, an interaction factor between time and latitude, so that:

$$
\mathrm{F}=\exp \left(\beta_{0}+\beta_{2} \mathrm{Y}+\beta_{3} \mathrm{Z}+\beta_{4} \mathrm{Y} \cdot \mathrm{Z}\right)
$$

Using equation 2 allowed the investigation of time trends in relation to latitude. In this modified function, all $\beta$ coefficients were estimated separately for boys and girls instead of using $\beta_{1} \mathrm{X}$.

A second modification was performed by adding $\beta_{5} U$ and $\beta_{6} V$, where $U$ and $V$ are factors considering other geographical differences:

$$
\mathrm{F}=\exp \left(\beta_{0}+\beta_{2} \mathrm{Y}+\beta_{3} Z+\beta_{5} \mathrm{U}+\beta_{6} \mathrm{~V}\right)
$$

As in equation 2 , all $\beta$ coefficients were estimated separately for boys and girls instead of using $\beta_{1} \mathrm{X}$. $\mathrm{U}$ is defined as follows: $1=$ cities with $>200000$ inhabitants; $2=$ suburbs around these cities; $3=$ cities with $>100000$ inhabitants; $4,5,6$, and $7=$ town districts with $>60000,>30000,>15000$, and >10 000 inhabitants, respectively; $8=$ villages of $<10000$ inhabitants; $9=$ very sparsely inhabited districts. $\mathrm{V}$ is defined as: $1=$ coastal 
Table 2 Variables of equation 1, estimating the probability for an infant of needing treatment for IHPS

\begin{tabular}{llll}
\hline & $\beta$ coefficient & $S E$ & p value \\
\hline$\beta_{0}$, constant & +0.88374 & 0.65640 & \\
X, sex; male = 0, female $=1$ & -1.37912 & 0.05421 & $<0.0001$ \\
Y, days after 31 Dec 1986 & -0.00013 & 0.00002 & $<0.0001$ \\
Z, latitude, degrees & -0.11022 & 0.01119 & $<0.0001$ \\
\hline
\end{tabular}

The value of a $\beta$ coefficient indicates the degree and direction of the effect of its variable in the function.

Table 3 Variables of equation 2, estimating the probability for a male or female infant of needing treatment for IHPS

\begin{tabular}{lllllll}
\hline & $\beta$, male & $S E$ & $p$ value & $\beta$,female & SE & p value \\
\hline$\beta_{0}$, constant & +1.97289 & 1.35467 & & +3.36770 & 2.91945 & \\
Y, days after 31 Dec 1986 & +0.00064 & 0.00074 & 0.3851 & -0.00125 & 0.00147 & 0.3944 \\
$Z$, latitude, degrees & -0.12833 & 0.02315 & $<0.0001$ & -0.17793 & 0.04999 & 0.0004 \\
$\mathrm{Y} Z$, (days) $\cdot$ (latitude) & -0.00001 & 0.00001 & 0.2878 & +0.00002 & 0.00003 & 0.4210 \\
\hline
\end{tabular}

The interaction term, $\mathrm{Y} \cdot \mathrm{Z}$, was used in order to specifically investigate whether variation in incidence with time $(\mathrm{Y})$ is related to latitude $(\mathrm{Z})$.

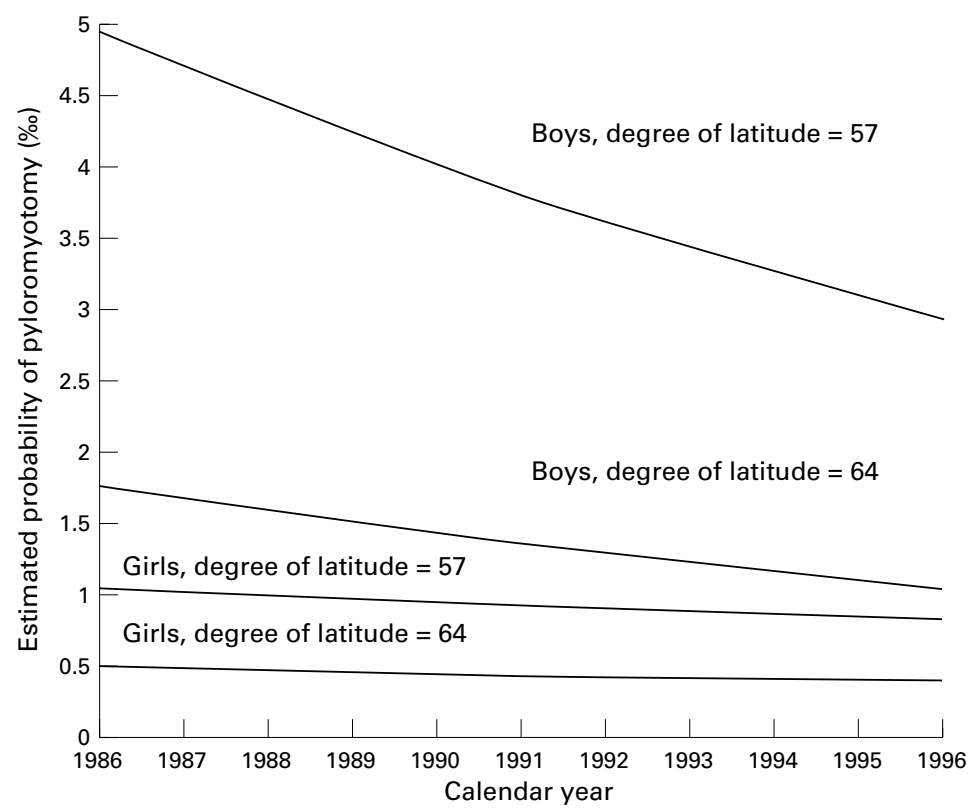

Figure 1 Estimated probability of undergoing pyloromyotomy for a male and female infant during 1987 to 1996 if born in the south of Sweden, in Halmstad, at the latitude of $57^{\circ}$, or if born in the north, in Umeà, at the latitude of $64^{\circ}$.

districts; 2 = inland districts situated more than $100 \mathrm{~km}$ from the coast; and $3=$ remote districts (mainly mountains and forests).

\section{Results}

Between 1987 and 1996, a total of 2157 infants (1738 boys, 419 girls), underwent pyloromyotomy for IHPS (see table 1). Tables 2, 3, and 4 present the $\beta$ coefficients with their standard errors and $\mathrm{p}$ values for equations 1,2 , and 3 , respectively. Figure 1 shows the estimated probability of undergoing pyloromyotomy for a male and female infant during 1987 to 1996 if born in the south or north of Sweden. The $p$ values of the $\beta$ coefficients for sex $(X)$, time trend $(\mathrm{Y})$, and latitude $(\mathrm{Z})$ were all significant $(p<0.0001)$. There was an overall decline in the incidence of IHPS during the study period, although when investigated separately the trend of decline for girls was not significant. The decline was not found to be related to latitude $(\mathrm{Y} \cdot \mathrm{Z})$. Regarding the geographical factors studied ( $\mathrm{U}$ and $\mathrm{V}$ ), there were no significant differences, although there was a trend towards a lower incidence in boys in urban areas.

\section{Discussion}

This study provides clear evidence of a decline in the incidence of IHPS between 1987 and 1996 in Sweden. The incidence of IHPS was almost three times higher in the south of Sweden than in the north. The registers employed for this study provide complete and reliable data: all medical facilities in Sweden are required to submit data on inpatients, their diagnoses, and surgical interventions; data submission is virtually complete for the past several years. This is possible because Swedish medical care is highly centralised in one nationwide organisation. The validity of the registers of the National Board of Health and Welfare has been confirmed in previous studies. $^{14}$ Furthermore, the fact that the patients identified from the National Patient Registry coincided closely with those who were identified as having undergone pyloromyotomy supports the validity of the registers used. Only one discrepancy was found-an adult patient with incorrect diagnosis of IHPS. The reporting procedures in paediatric and surgical clinics did not change during the study period. Therefore the change in incidence could not be explained by registration procedures.

Previous epidemiological studies have shown various different trends. No change was identified in three studies - in Denmark from 1950 to $1984,{ }^{15}$ in British Columbia during the $1970 \mathrm{~s},{ }^{16}$ and in Western Australia from 1971 to $1984 .{ }^{17}$ An increasing incidence was found in Minnesota from 1950 to $1984,{ }^{1}$ in central Scotland and other parts of $\mathrm{UK}^{2-5}$ and in Germany during the 1970 s and 1980 s. $^{6}$ Three previous studies showed a decline like ours - in Northern Ireland before $1970,{ }^{7}$ in Saskatchewan from 1970 to $1985,{ }^{8}$ and in New York State from 1983 to $1990 .{ }^{9}$ The latter study was by far the largest, including 4063 cases, and showed a fall in incidence from 2.4 to $1.7 / 1000$ births. White race and male gender were associated with an increasing incidence of IHPS; low birth weight, increased maternal age, and high birth order were associated with a reduced

Table 4 Variables of equation 3, estimating the probability for a male or a female infant of needing treatment for IHPS

\begin{tabular}{lllllll}
\hline & $\beta$, male & SE & p value & $\beta$, female & SE & $p$ value \\
\hline$\beta_{0}$, constant & +3.52717 & 0.76298 & & -0.61042 & 1.527605 \\
Y, days after 31 Dec 1986 & -0.00015 & 0.00002 & $<0.0001$ & -0.00007 & 0.00005 & 0.1665 \\
Z, latitude, degrees & -0.15599 & 0.01322 & $<0.0001$ & -0.10999 & 0.02639 & $<0.0001$ \\
U, urbanisation, rated 1-9 & +0.02076 & 0.01191 & 0.0814 & -0.01816 & 0.02457 & 0.4598 \\
V, geographical location, rated 1-3 & -0.01202 & 0.03697 & 0.7451 & +0.04351 & 0.07163 & 0.5600 \\
\hline
\end{tabular}

The value of a $\beta$ coefficient indicates the degree and direction of the effect of its variable in the function. Urbanisation was rated from 1 to 9 , with low values for urban areas. Geographical location was rated from 1 to 3, with 1 for coast and 3 for inland areas. 
incidence. A study from California on 1963 cases of IHPS during 1983 to 1988 showed no clear decline, although some other findings were confirmed: the incidence among white infants was 2.4 and among Hispanic infants $1.8 / 1000$ births while it was 0.7 and $0.6 / 1000$ births among black and Asian infants, respectively. ${ }^{18}$ The highest incidences have been reported in the UK, ranging from 3.5 to $8.8 / 1000$ births. $^{1-3}$ In the Saskatchewan study bottle feeding was 2.9 times more prevalent among the IHPS infants. ${ }^{8}$

From the results of these various studies, it appears that IHPS occurs with a varying frequency over time and in different regions with incidences ranging between 1.7 and $8.8 / 1000$ births. Occurrence depends on genetic factors, gender and race being affected differently, although minor environmental factors like type of feeding also appear to be important.

In our study, the finding that the incidence of IHPS was almost three times higher in the south of Sweden compared to the north could indicate unknown environmental factors of importance. We found that the substantial decline in incidence occurred throughout the whole country during the ten year study period. This change in incidence might be explained if IHPS is being transmitted like an infectious disease, although the low incidence would suggest that individual susceptibility would have to be variable and infrequent. This susceptibility may depend on both hereditary and environmental factors. It is impossible to say whether environmental or genetic factors are most important in determining the difference in incidence between northern and southern Sweden. The only obvious difference between the north and south is the difference in climate. The incidence of IHPS at the end of the study period, especially in northern Sweden, is the lowest reported so far among white infants.
This study was supported by grants from the Göteborg Children's Hospital Research Foundation, and The Wilhelm and Martina Lundgren's Research Foundation II.

1 Jedd MB, Melton LJ III, Griffin MR, et al. Trends in infantile hypertrophic pyloric stenosis in Olmsted County, Minnesota, 1950-84. Paediatr Perinatol Epidemiol 1988;2:14857.

2 Kerr AM. Unprecedented rise in incidence of infantile hypertrophic pyloric stenosis. BMF 1980;281:714-15.

3 Knox EG, Armstrong E, Haynes R. Changing incidence of infantile hypertrophic pyloric stenosis. Arch Dis Child 1983;58:582-5.

4 Webb AR, Lari J, Dodge JA. Infantile hypertrophic pyloric stenosis in South Glamorgan 1970-9. Arch Dis Child 1983; 58:586-90.

5 Tam PKH, Chan J. Increasing incidence of hypertrophic pyloric stenosis. Arch Dis Child 1991;66:530-1.

6 Mason PF. Increasing infantile hypertrophic pyloric stenosis? Experience in overseas military hospital. $\mathcal{F} R$ Coll Surg Edinb 1991;36:293-4.

7 Dodge JA. Infantile hypertrophic pyloric stenosis in Belfast, 1957-1969. Arch Dis Child 1975;50:171-8.

8 Habbick BF, Khanna C, To T. Infantile hypertrophic pyloric stenosis: a study of feeding practices and other possible causes. Can Med Assoc f 1989;140:401-4.

9 Applegate MS, Druschel CM. The epidemiology of infantile hypertrophic pyloric stenosis in New York state 1983-90. Arch Pediatr Adolesc Med 1995;149:1123-9.

10 Socialstyrelsen, National Board of Health and Welfare in Sweden. Classification of diseases, according to WHO, 9th revision of International Classification of Diseases ICD-9. Stockholm: Liber, 1987.

11 Socialstyrelsen, National Board of Health and Welfare in Sweden. Classification of operations. Stockholm: Liber, 1985

12 SCB, National Central Bureau of Statistics in Sweden. Population changes. Tables on population changes in counties and municipalities. Official Statistics of Sweden, annual publication.

13 Breslow NE, Day NE. Unconditional logistic regression for large strata. Statistical methods in cancer research, Vol. I. IARC scientific publication no. 32. Lyon, France: WHO, International Agency for Research on Cancer, 1980:192-243.

14 DeFaire U, Friberg L, Lorich U, Lundman T. A validation of cause-of-death certification in 1156 deaths. Acta Med Scand 1976;200:223.

15 Rasmussen L, Green A, Hansen LP. The epidemiology of infantile hypertrophic pyloric stenosis in a Danish Population 1950-84. Int f Epidemiol 1989;18:413-17.

16 Walpole IR. Some epidemiological aspects of pyloric stenosis in British Columbia. Am f Genet 1981;10:237-44.

17 Hitchcock NE, Gilmour AI, Gracey M, Burke V. Pyloric stenosis in Western Australia, 1971-84. Arch Dis Child 1987;62:512-13.

18 Schechter R, Torfs CP, Bateson TF. The epidemiology of infantile hypertrophic pyloric stenosis. Paediatr Perinatal Epidemiol 1997;11:407-27. 